\title{
Dois gestos de leitura do Curso de Linguística Geral, de Saussure: do essencial aos arcanos
}

\section{Two readings of Sausurre's Course in General Linguistics: from the basics to the arcanes}

\author{
Clemilton Lopes Pinheiro* \\ clemiltonpinheiro@hotmail.com \\ Universidade Federal do Rio Grande do Norte \\ Gustavo Augusto Lima de Sousa** \\ gustavoyup@hotmail.com \\ Universidade Federal do Rio Grande do Norte
}

RESUMO: Este trabalho se situa no contexto das perspectivas de apresentação e problematização do Curso de Linguística Geral (CLG), de Ferdinand de Saussure. Elegemos dois trabalhos que circulam no contexto universitário brasileiro e que, de forma geral, apresentam a finalidade comum de introduzir o CLG a leitores não iniciados em Linguística: Para compreender Saussure, de Castelar de Carvalho (1997 [1976]), e o capítulo "O Curso de Linguística Geral: modesto ensaio de releitura" (MER) do livro Em busca de Ferdinand de Saussure, de Michel Arrivé (2010 [2007]). Considerando, portanto, essa finalidade dos dois trabalhos, nosso objetivo é refletir sobre a maneira como ela é cumprida e quais consequências pode trazer. Concluímos que o primeiro opta pela síntese, com intuito fundamentalmente didático; o outro, sem deixar de ser didático, opta pela problematização, em um percurso progressivo e propedêutico. Trata-se, nesse sentido, de uma reflexão que pode impactar o debate sobre formação de professores e pesquisadores no campo dos estudos da linguagem.

PALAVRAS-CHAVE: CLG; Epistemologia da linguística; Saussurianismo.

ABSTRACT: The present paper is situated in the context of perspectives of presentation and problematization of Ferdinand de Saussure's Course in General Linguistics (CGL). We selected two works that circulate in the Brazilian academic context and which, in general, have the common purpose of introducing the CGL to non-initiated readers in linguistics: Para compreender Saussure, by Castelar de Carvalho (1997 [1976]), and the chapter "O Curso de Linguística Geral: modesto ensaio de releitura" (MER), in the book Em busca de Ferdinand de Saussure, by Michel Arrivé (2010 [2007]). Therefore, considering the purpose of these two works, our objective is to reflect about the way this purpose is achieved and what consequences it may bring. We conclude that the first work opts for a synthetic approach, with a

\footnotetext{
* Doutor em Letras, área de Filologia e Linguística Portuguesa. Professor de Linguística no Programa de Pós-Graduação em Estudos da Linguagem e do Departamento de Letras da Universidade Federal do Rio Grande do Norte.

** Graduado em Design, licenciando em Letras/Inglês. Mestrando no Programa de Pós-Graduação em Estudos da Linguagem da Universidade Federal do Rio Grande do Norte.
} 
fundamentally didactic intent; the second, without refraining to be didactic, opts for a problematized approach, in a progressive and propaedeutic route. In this regard, this discussion is a reflection that can affect the debate on the training of teachers and researchers in the field of language studies.

KEYWORDS: CGL, Epistemology of linguistics; Saussurisme.

\section{Introdução}

A contribuição mais comumente reportada de Ferdinand de Saussure para os estudos da linguagem é a que foi fixada no Curso de Linguística Geral (CLG), tanto que representa um momento decisivo na história da Linguística como ciência. Como assinalam Colombat, Fournier e Puech (2010, p. 25), "ele permanece, enfim, ainda hoje, um texto de introdução à Linguística nos inúmeros cursos universitários no mundo inteiro". É verdade afirmar que os trabalhos que divulgam, explicam ou analisam o conteúdo dessa obra abundam, mas é igualmente correto dizer que as perspectivas de compreensão desse conteúdo são distintas (ver, por exemplo, SOFIA, 2015).

Este trabalho se situa nesse contexto das perspectivas de apresentação e problematização do CLG. Do oceano de trabalhos que exploram esse tema, elegemos dois, que circulam no contexto universitário brasileiro e que, de forma geral, apresentam a finalidade comum de introduzir o CLG a leitores não iniciados em Linguística: Para compreender Saussure, de Castelar de Carvalho (1997 [1976]), e o capítulo "O Curso de Linguística Geral: modesto ensaio de releitura", do livro Em busca de Ferdinand de Saussure, de Michel Arrivé (2010 [2007]). Considerando, portanto, essa finalidade dos dois trabalhos, nosso objetivo é refletir sobre a maneira como ela é cumprida e quais consequências pode trazer, já que é tomada a partir de gestos de leitura diferentes. Entendemos que esse tipo de reflexão é importante para o debate sobre formação de professores universitários e pesquisadores no campo dos estudos da linguagem.

Nossa reflexão segue um percurso de três etapas. Primeiro, contextualizamos, de forma breve, os dois trabalhos, pois consideramos que a compreensão acerca do modo como a finalidade de cada trabalho é cumprida passa pelas suas características, sejam editorias ou de concepção. Em seguida, retomamos a maneira como cada autor (o que chamamos de gesto de leitura) apresenta as principais noções teóricas presentes no CLG: signo, valor, língua, fala, relações sintagmáticas, relações 
associativas, sincronia e diacronia. Por fim, identificamos, com base nessa retomada, as principais características dos dois gestos de leitura, que configuram a maneira como cada autor cumpre a finalidade de introduzir o CLG a leitores não iniciados.

\section{Contextualização}

Não há muita informação biográfica disponível e de fácil acesso sobre o professor Castelar de Carvalho. Não há, inclusive, curriculum cadastrado na Plataforma Lattes (CNPq). Na lista de colaboradores do número 27/28 da revista Confluência, há uma breve biografia na qual ele é apresentado como "professor Doutor de Língua Portuguesa da Faculdade de Letras da Universidade Federal do Rio de Janeiro" (CONFLUÊNCIA, 2004, p. 371). No entanto, o nome de Castelar de Carvalho é bastante conhecido e citado, sobretudo nos cursos de Letras nas universidades brasileiras em função da sua autoria do livro Para compreender Saussure (PCS), publicado em 1976, e que, segundo Barbosa (2014, p. 282), "chegou à vigésima edição em 38 anos de existência".

O objetivo do livro é explicitado na apresentação, feita por Silvio Elia:

O trabalho tem finalidades didáticas e destina-se aos alunos dos nossos cursos superiores de Letras e Comunicação. (...) É a primeira vez que, em língua portuguesa, se faz uma apresentação sistemática e coerente dos fundamentos metodológicos da linguística saussuriana. Os nossos alunos de Letras geralmente entram em contato com a Linguística logo no primeiro ano de suas atividades universitárias (ELIA, 1997, p. 8).

Trata-se, portanto, de um livro cujo status é o de um "manual de consulta" (CARVALHO, 1997, p. 13), que foi concebido, justamente, no contexto de experiência de sala de aula em um curso de introdução à Linguística, inicialmente de graduação e depois de pós-graduação, como conta Barbosa (2014, p. 280):

A iniciativa nos remete diretamente a Silvio Elia, a quem o manual é dedicado. $O$ autor foi seu assistente na cadeira de Linguística da FAHUPE, além de ter sido seu aluno dessa mesma disciplina no Mestrado da UFF, em 1973. Destaque-se que, na Bibliografia, as Notas de aula do Prof. SílVIO ELIA, por ocasião do curso já mencionado, ocupam a primeira posição como referência de base para o estudo. 
O livro se organiza em três partes distribuídas em oito capítulos que, juntamente com o apêndice, somam um total de cento e oitenta e cinco páginas. A primeira parte se dedica a contextualizar o desenvolvimento dos estudos linguísticos e fornece um breve percurso desses estudos até a publicação do CLG. A segunda parte traz uma breve biografia de Saussure, mas o foco é a apresentação propriamente dita do conteúdo do CLG: teoria do signo linguístico, língua/fala, sincronia/diacronia, relações sintagmáticas e paradigmáticas, noção de valor. Por fim, a terceira parte explora a repercussão e algumas propostas de desenvolvimento das ideias presentes no CLG. Deve-se considerar que essa terceira parte não foi revista e atualizada nas edições mais recentes do livro. Essa terceira parte, portanto, ainda está circunscrita historicamente à década de 1970, momento de publicação da primeira edição do livro.

Quanto a Michel Arrivé, falecido em abril de 2017, foi professor de linguística e de semiótica na Universidade Paris Naterre. Segundo Puech (2017, p. 3), ele foi um "gramático atípico", pois sua carreira foi marcada pela "diversidade de interesse e de atividades". No entanto, "é sem dúvida no domínio saussuriano ou 'saussurológico' que o talento de M. Arrivé encontrou nesses últimos dez anos seu campo de exercício mais dinâmico". Destaca-se, nesse campo, a trilogia À la recherche de Ferdinand de Saussure (ARRIVÉ, 2007), Du côté de chez Saussure (ARRIVÉ, 2008) e Saussure retrouvé (ARRIVÉ, 2016). O primeiro livro dessa trilogia, traduzido para o português em 2010 (ARRIVÉ, 2010), "permitirá ao leitor iniciado situar melhor o pensamento de Saussure no campo das ciências da linguagem. E ao leitor que se inicia, ele possibilita um encontro com um mestre não dogmático, ao destacar suas hesitações e angústias [...]" (MARCIONILO, 2010 p. 8).

Além de um prefácio e da introdução, o livro conta com oito capítulos que se organizam sobre a égide de duas vertentes, segundo assinala Saint-Gérard (2009, p. 58):

O trabalho de M. Arrivé, que expõe Saussure entre duas representações opostas (farol e sombra, ambas carregadas pelos mistérios da noite), nos apresenta, em seus nove capítulos, os pilares de um entendimento global do pensamento saussuriano sobre a linguagem finalmente desprovido de qualquer dogmatismo sectário.

O segundo capítulo, "O Curso de Linguística Geral: um modesto ensaio de releitura" (MER), "constitui um esforço de releitura do Curso de linguística geral" (ARRIVÉ, 2010, p. 16). Nesse sentido, encontramos, nesse capítulo de 52 páginas, 
os principais temas do CLG, dispostos de forma a compor um quadro do objeto e da tarefa da Linguística: a concepção de signo e suas características (arbitrariedade e linearidade), a distinção entre relações sintagmáticas e associativas e esquematização da sincronia e da diacronia como cruzamento dos eixos da simultaneidade e da sucessividade.

\section{Dois gestos de leitura do CLG}

A noção de signo linguístico é a que recebe uma atenção mais ou menos equilibrada, em termos de extensão, entre os dois gestos de leitura.

No caso de Carvalho, o ponto inicial da explanação sobre o signo é a definição saussuriana de língua como um sistema de signos. Essa definição é seguida por uma explicação do autor daquilo que forma um signo: "[...] união do sentido e da imagem acústica" (CARVALHO, 1997, p. 31). Essa passagem, largamente repetida na obra de Carvalho, diz respeito à terceira característica da língua, enumerada por Saussure no CLG, após a discussão do circuito da fala (SAUSSURE, 1995, p. 23). Compreendemos que, por extensão, a leitura de Carvalho sugere que o signo também pode ser visto como a união do sentido e da imagem acústica, mesmo que depois o termo sentido é substituído por significado.

No desenvolvimento dessa definição, Carvalho busca precisar o que cada face do signo linguístico implica. Ele esclarece que "[...] o que Saussure chama de sentido é a mesma coisa que conceito ou ideia, isto é, a representação mental de um objeto ou da realidade social em que nos situamos [...]" (CARVALHO, 1997 p. 32-33). E, logo em seguida, afirma que, "[...] para Saussure, conceito é sinônimo de significado, algo como a parte espiritual da palavra, sua contraparte inteligível em oposição ao significante, que é sua parte sensível" (ibidem, p. 33). Vemos que a terminologia específica do CLG é introduzida de forma bastante direta: significado e significante são traduzidos por Carvalho como o inteligível e o sensível, respectivamente. $\mathrm{E}$, assim, ele conclui: "Podemos designar, portanto, o significante como a parte perceptível do signo e o significado como sua parte inteligível" (CARVALHO, 1997, p. 34).

Já a discussão de Arrivé sobre signo linguístico começa pela questão da terminologia. O linguista francês dedica algumas páginas para mostrar, recorrendo às fontes manuscritas, a dificuldade que Saussure sentiu em estabelecer os termos. A 
exposição é apoiada pela passagem do CLG em que Saussure diz que se contenta com o uso do termo signo por não saber um substituto melhor (SAUSSURE, 1995, p. 81). Além disso, o linguista francês começa a discussão pondo em foco o que Carvalho havia optado em pôr como um adendo: a escolha de Saussure em remover o referente do signo. Na leitura de Arrivé, a importância da menção à exclusão do referente se dá por dois motivos: primeiro, porque reforça a tomada de posição de Saussure em recusar considerar a língua como nomenclatura; e, segundo, porque ressalta a intenção de Saussure em garantir a independência da língua em relação ao que é externo a ela, pressupondo aí o princípio da arbitrariedade e, ulteriormente, permitindo o estabelecimento da noção de valor.

Arrivé não se preocupa em oferecer uma definição de signo, muito menos de significante e de significado. O que lhe interessa, na verdade, é ressaltar a formulação conceitual com base na inovação da escolha terminológica de Saussure em utilizar os termos significante e significado para, respectivamente, imagem acústica e conceito, pois essas duas denominações garantem às faces do signo um desligamento de qualquer "característica substancial própria" (ARRIVÉ, 2010, p. 56). Podemos compreender, nesse caso, que a leitura aponta que a decisão de Saussure pelos termos significante e significado não é aleatória: é consciente na medida em que procura evitar quaisquer outras denominações que poderiam, equivocadamente, aludir a um caráter material que o signo não possui. Desse modo, Arrivé não reintroduz uma definição das faces do signo, mas aponta a problemática dessa definição. Quanto ao signo, dedica-se a lembrar que ele é "[...] finalmente definido como o 'total' constituído pela associação do significante e do significado" (ARRIVÉ, 2010, p. 56).

Em ambos os textos, após a explicitação do signo linguístico e de suas partes constituintes, os princípios que regem o signo saussuriano são apresentados.

No texto de Carvalho, a arbitrariedade do signo é apresentada logo depois da alusão à exclusão, feita por Saussure, do referente. Nesse ponto, a explicação é direta (não há nenhuma explicação sobre a instituição da arbitrariedade) e são usados os mesmos exemplos do CLG sobre a relação não-motivada entre significante e significado. No entanto, Carvalho não se restringe à apresentação do princípio e apresenta o que ele chama de críticas ao princípio da arbitrariedade. Carvalho compreende que as críticas ao caráter arbitrário do signo passam pela impossibilidade de se atribuir um dado significante numa língua $A$, que está relacionado a um 
determinado significado, a um suposto significado idêntico presente numa língua B, que possui um significante diferente.

Dessa maneira, Carvalho identifica como a crítica fundamental ao arbitrário do signo uma comparação, posta pelo autor como inadequada, entre signos de dois sistemas diferentes, em vez da consideração da relação interna significado e significante. Essa crítica é rebatida numa explanação que é sustentada pela noção saussuriana de valor, mesmo que essa noção não seja mencionada nesse ponto do texto. É interessante observar que, embora pelo modo oblíquo do rebate a uma crítica, a arbitrariedade e a noção de valor se encontram na leitura de Carvalho implicitamente.

$\mathrm{Na}$ leitura de Arrivé, essa relação entre o princípio da arbitrariedade e a noção de valor é ressaltada. No entanto, ela não é o foco da exposição de Arrivé a respeito desse princípio. Após a discussão das aparentes exceções levantadas pelo próprio Saussure à arbitrariedade da relação significante-significado, bem como o caso da motivação relativa, Arrivé põe em relevo o que parece ser o nó da questão em sua leitura: como Saussure procurou provar o princípio da arbitrariedade.

Conforme Arrivé, ao tentar provar o arbitrário da relação entre significante e significado com a comparação entre a palavra francesa bœuf e a alemã oks, Saussure "deslizou" e passou a considerar não a arbitrariedade entre as duas faces do signo, mas entre o signo e o referente. Assim, Arrivé afirma categoricamente que "[...] é incontestável, o CLG, em quase perfeito acordo na versão padrão e nas fontes manuscritas, desloca a relação entre o significante e o significado, mas explica o fenômeno fazendo intervir o referente" (ARRIVÉ, 2010, p. 62). Desse modo, na leitura de Arrivé, o princípio da arbitrariedade não é demonstrado por Saussure. $\mathrm{O}$ autor francês chega mesmo a se perguntar se é possível tal demonstração e passa algumas páginas problematizando a questão.

Esse problema encontrado na demonstração de Saussure por Arrivé não é comentado por Carvalho, que aponta como crítica ao princípio da arbitrariedade uma outra relação que contestaria, na verdade, a noção de valor. Além disso, de todo modo, em Arrivé, a questão não é tanto apresentar críticas ao arbitrário do signo em si mesmo, tal como o é em Carvalho, mas problematizar o modo como Saussure procura demonstrar o princípio da arbitrariedade e sobretudo destacar sua finalidade: estabelecer a noção de valor como base na qual se explica o funcionamento do signo no sistema. 
No que diz respeito ao segundo princípio, o caráter linear do significante, de início, Carvalho ressalta a importância desse princípio, tendo em face as relações sintagmáticas. Trata-se de uma linha de raciocínio pouco comum no texto de Carvalho: uma determinada noção saussuriana é relacionada intimamente a uma outra. No entanto, em vez de ir diretamente à descrição da linearidade do significante, o linguista brasileiro prefere começar com uma menção ao caráter discreto dos elementos linguísticos, recuperando André Martinet, um dos leitores de Saussure.

Ao fazer isso, o gesto de leitura sobre o caráter do significante busca enfatizar que um elemento linguístico está presente ou não, é realizado ou não: "Ou pronunciamos 'vaca' ou 'faca'” (CARVALHO, 1997, p. 47). Explicado desse modo, o caráter linear do significante é lido como uma consequência lógica da impossibilidade da concomitância dos elementos linguísticos, que devem se suceder. Essa explicação parece ser sustentada sobretudo na passagem do CLG em que Saussure pontua que o caráter linear da língua "[...] exclui a possibilidade de pronunciar dois elementos ao mesmo tempo" (SAUSSURE, 1995, p. 142) ${ }^{1}$. Assim ressaltada essa característica dos elementos linguísticos, Carvalho (1997, p. 47) conclui: "A língua, em seu funcionamento, pode ser descrita, portanto, como uma sucessão de unidades discretas [...]".

Após essa conclusão, parece-nos que Carvalho tem consciência da descrição dada à língua (que é sistema de signos e, logo, implica também o significado) como uma sucessão de unidades, e então decide esclarecer que "[...] a linearidade é do significante e não do significado" (CARVALHO, 1997, p. 48). Para explicar isso, mais uma vez, repete que esse princípio exclui uma das faces do signo, pois, condizente com o modo como havia anteriormente caracterizado o significante, é "a parte material do signo" que está sujeita à linearidade, enquanto o pensamento é reticular.

Para Arrivé, o princípio da linearidade do significante é mais complexo e mais ambíguo que o da arbitrariedade. A razão disso está em duas contradições que ele aponta no pensamento de Saussure. A primeira delas é justamente o fato de o segundo princípio se aplicar apenas ao significante, enquanto o primeiro compreende o signo como um todo. Ademais, se o signo é uma unidade de duas faces inseparáveis, Arrivé se questiona como é possível separá-las de tal modo que só uma

\footnotetext{
${ }^{1}$ Por hora, deixemos passar a troca de significante por língua na passagem citada e voltemos a ela um pouco mais adiante, pois, embora não suscite nenhum comentário na leitura de Carvalho, ela certamente chama a atenção de Arrivé.
} 
delas esteja submetida à linearidade. Esse problema é retomado quando Arrivé faz menção à passagem do CLG, anteriormente citada aqui, em que Saussure fala do "caráter linear da língua". Para o linguista francês, o problema está claramente posto: se falamos do caráter linear da língua e a língua é um sistema de signos, então é o signo como um todo que está sujeito à linearidade. No entanto, Saussure nada diz sobre uma linearidade do significado. Como explicar essa restrição?

Após uma problematização com o que é apresentado em diferentes fontes, Arrivé conclui que, por trás da restrição da linearidade ao significante, está a consideração de que é material e sujeito ao tempo. Surge, então, aqui, a outra contradição apontada por Arrivé: como pode ser o significante material se ele é estritamente definido como mental por Saussure? O problema se resume da seguinte forma: "Percebemos a contradição que esse novo ponto de vista desencadeia. Em um ponto, o significante é dado como linear pela simples razão de sua materialidade. Mas em outro, ele é dado como não material" (ARRIVÉ, 2010, p. 73).

A posição de Arrivé sobre essa questão é exposta, mais adiante, quando ele trata sobre a noção de diacronia. Para ele, Saussure pensa a sucessão das palavras não apenas como uma sucessão de fonemas. Além disso, considera a ação do tempo sobre a fala. Como base na "exigência de conformidade conceitual", Saussure supõe que um princípio aplicado a uma face do signo também o seja irremediavelmente para o signo como um todo.

A noção de valor é o último postulado saussuriano apresentado por Carvalho, no seu PCS. Ele começa a exposição com a célebre passagem do CLG de que só existem diferenças na língua e procura demonstrar que a língua "[...] não está na substância fônica, nem na substância gráfica, tampouco existe unicamente nas ideias, nos conceitos" (CARVALHO, 1997, p. 133).

No entanto, em vez de prosseguir com uma discussão sobre a instituição das diferenças na língua, e embora apresente a metáfora da folha de papel bem como o chamado "esquema das ideias confusas", o linguista brasileiro quer mostrar como a língua articula o plano dos sons e o das ideias para, em seguida, apresentar a proposta da dupla articulação de André Martinet.

Se, na discussão do caráter linear do significante, a menção a Martinet visava a "prova" da impossibilidade de se produzirem dois sons ao mesmo tempo, aqui, ela procura, de algum modo, demonstrar o motivo com base no qual a língua é apenas forma para Saussure. Vejamos como essa ligação é feita: Carvalho aponta que toda 
relação entre sons e ideias, na língua, "[...] constitui uma forma e não uma substância", portanto, "[...] Saussure lançou os fundamentos do que hoje é conhecido em Linguística como ‘o princípio da dupla articulação da linguagem' [...]” (1997, p. 135).

Ao passar a discutir as propostas de Martinet sobre a dupla articulação da linguagem, a noção de valor é momentaneamente deixada de lado, mas é, em seguida, recuperada e explicada. Carvalho resume que "[...] a) o valor resulta sempre e necessariamente de uma relação; b) o valor linguístico é sempre um valor semântico, um valor significativo" (1997, p. 137).

Nesse resumo sobre a noção de valor, é interessante notar que Carvalho restringe a aplicação do valor ao nível do significado, excluindo o significante. Essa leitura difere da feita por Arrivé, já que, para ele, "o valor intervém necessariamente em três objetos distintos: por um lado, cada uma das faces do signo - significado e significante - e, por outro, o signo em sua totalidade" (ARRIVÉ, 2010, p. 82).

No entanto, existem outras diferenças nos dois gestos de leitura a respeito da noção de valor. Se, de certo modo, Carvalho tenta mostrar como a dupla articulação da linguagem explica a noção de valor, Arrivé faz um movimento diferente e interpreta essa noção como consequência da arbitrariedade do signo. Para Arrivé, instituir o valor linguístico implica necessariamente a consideração da arbitrariedade da relação entre significante e significado, pois

[...] para que a língua possa ser definida como um sistema de valores puros, é imprescindível que as relações entre as unidades linguísticas não sejam determinadas por nada de externo à língua: a pressão do referente - aquela que faria intervir nas relações entre signos "um elemento imposto de fora” - aqui deve ser nula (ARRIVÉ, 2010, p. 80).

Dessa condição, nas palavras de Arrivé, "derivada" da arbitrariedade, conclui-se que, na verdade, as relações entre os signos e o valor de cada um deles é o "[...] verdadeiro estatuto das unidades linguísticas, mais do que a associação de um significado com um significante" (ARRIVÉ, 2010, p. 82).

Há outros pontos ressaltados por Arrivé a respeito da noção de valor, que não são objetos de atenção de Carvalho. O primeiro é a questão sobre o que é consciente e inconsciente na língua. Essa questão é posta a partir da passagem do $C L G$ em que Saussure afirma que somente as diferenças entre os signos chegam até "as regiões da consciência" (SAUSSURE, 1995, p. 137). O segundo é "a reabilitação da escrita" feita por Saussure ao exemplificar a noção de valor: a diferença entre os caracteres 
gráficos também está baseada numa noção de valor, pois a escrita, separada definitivamente da língua por Saussure, assume status próprio e independente do sistema de signos que é a língua.

Um último ponto é a negatividade e a positividade das unidades linguísticas ${ }^{2}$. 0 linguista francês procura problematizar uma contradição que, segundo ele, o próprio Saussure nota: a positividade do signo e a negatividade dos elementos que o constituem. Arrivé levanta a questão de que a introdução dessa positividade no signo, apesar de toda possível contradição que ela conseguiria suscitar, poderia não ser o gesto mesmo que possibilita a comunicação, visto que se tudo na língua fosse negativo, "[...] a comunicação seria, por definição, impossível” (ARRIVÉ, 2010, p. 86).

$\mathrm{Na}$ ordem sequencial de seu gesto de leitura, a apresentação do par língua/fala é a primeira dicotomia explorada por Carvalho depois da discussão do signo linguístico. Sua exposição começa por uma menção à própria organização das noções saussurianas em dicotomias para, em seguida, explanar sobre a noção de língua.

Carvalho parte de três concepções que ele identifica no CLG: a língua como acervo linguístico, a língua como instituição social e a língua como realidade sistemática e funcional. Em cada uma, os comentários são breves e toda a exposição toma como foco a seguinte passagem do CLG: "constitui-se [a língua] num sistema de signos onde, de essencial, só existe a união do sentido e da imagem acústica" (SAUSSURE, 1995, p. 23). Carvalho chama atenção para o fato de que "forma", na distinção forma/substância, é "[...] usada no sentido filosófico, isto é, como essência, e não no sentido estético, como aparência". Embora o esclarecimento procure afastar uma compreensão de forma em sentido corriqueiro, a menção ao "sentido filosófico" torna a passagem vaga, porque a ideia não é desenvolvida.

Há ainda uma tentativa de relacionar a concepção de língua saussuriana, essencialmente baseada no social e no compartilhado por uma comunidade, com as ideias de Durkheim sobre o fato social, mas também sobre a coerção de uma instituição social aos indivíduos. Já a concepção de fala indicaria uma influência de Gabriel Tarde no pensamento de Saussure. Uma crítica à concepção de língua e de fala saussuriana é ainda feita com base na noção de norma, proposta por Eugenio Coseriu.

\footnotetext{
${ }^{2}$ Essa questão é abordada brevemente por Carvalho com base em uma citação do linguista Maurice Le Roy, mas não apresenta o mesmo caráter especulativo da discussão de Arrivé.
} 
Na exposição de Arrivé não há mais que alguns parágrafos para discorrer sobre a noção de língua. O gesto de leitura, nesse caso, recebe uma visada psicanalítica, uma vez que a noção de fala como um "não-todo" é associada ao pensamento de Lacan (ARRIVÉ, 2010, p. 50). Além disso, Arrivé procura primeiro destacar a língua da linguagem e, posteriormente, a fala da língua, seguindo, portanto, o mesmo percurso do CLG.

No que diz respeito à fala, Carvalho destaca a impossibilidade de estudo sistemático:

[...] como ciência só pode estudar aquilo que é recorrente, constante, sistemático. Os elementos da langue podem ser, quando muito, variáveis, mas jamais apresentam a inconstância, a irreverência, a heterogeneidade característica da parole, a qual, por isso mesmo, não se presta a um estudo sistemático (CARVALHO, 1997, p. 65).

Nesse sentido, a ciência linguística só é possível se toma como objeto de estudo a língua e não a fala. Carvalho chega mesmo a mencionar o aceno de Saussure a uma linguística da fala, mas ele põe em suspeita esse gesto, com base no que pensa o linguista Georges Mounin, pois há "[...] dúvida da autenticidade dessa postulação por parte do mestre; Mounin prefere atribuí-la a Bally e Sechehaye [...]" (CARVALHO, 1997, p. 66). Essa é uma das poucas vezes, senão a única, em que Carvalho procura pôr em discussão a organização do CLG feita pelos editores.

Nesse ponto, Arrivé realiza um gesto bastante diferente. Para ele, embora a hierarquização da língua sobre a fala seja inegável no CLG, não é correto afirmar a exclusão da fala ou a exclusividade do estudo da língua por ela mesma. Para o linguista francês, apoiado nas anotações de Constantin, o movimento de Saussure é muito mais de uma distinção de "[...] dois campos próximos e a decisão de se concentrar em um deles" (ARRIVÉ, 2010, p. 52). Arrivé para nesse ponto e apenas acrescenta uma breve menção ao desenvolvimento dado por Benveniste às reflexões de Saussure.

No que diz respeito às relações sintagmática e associativa, no $P C S$, Carvalho destaca, de início, o princípio que fundamenta a relação sintagmática: o caráter linear do significante. Além disso, Carvalho explica a relação entre o sintagma e o valor linguístico, pontuando que "[...] um termo passa a ter valor em virtude do contraste que estabelece com aquele que o precede ou lhe sucede, 'ou a ambos', visto que um termo não pode aparecer ao mesmo tempo que outro" (CARVALHO, 1997, p. 109). O 
gesto de Arrivé é o mesmo: as relações sintagmáticas são igualmente conectadas pela linearidade. Trata-se de relações "[...] que se estabelecem entre as unidades consecutivas do discurso" (ARRIVÉ, 2010, p. 87).

Os dois gestos se assemelham também ao apontarem a variabilidade da extensão do sintagma. Tanto Carvalho como Arrivé se dedicam a comentar que Saussure imaginou a possibilidade de combinação de unidades na formação de sintagmas, mas não definiu exatamente os limites dessas combinações. Arrivé, por exemplo, chama atenção para o emprego do "etc", quando Saussure apresenta exemplos de sintagmas.

Os dois gestos de leitura sobre as relações associativas também não se distanciam muito. Carvalho faz uma exposição um pouco mais longa, e recorre às reflexões de Hjelmslev. Já Arrivé é breve e se atem apenas a citações do CLG. No entanto, enquanto o linguista francês conclui sua exposição com um resumo das duas relações, Carvalho propõe a diferença entre "oposição contrastiva" e "oposição distintiva". O linguista brasileiro faz ainda um adendo em que classifica uma série de sintagmas da língua portuguesa em fônicos, mórficos ou sintáticos. Não se trata, é claro, de um tema explorado por Saussure, mas de uma retomada de pressupostos do distribucionalismo.

No que diz respeito à dicotomia sincronia/diacronia, por um lado, ambos os gestos de leitura destacam que a noção de valor e o princípio da arbitrariedade estão implicados no par sincronia/diacronia. Por outro lado, o primeiro acentua a natureza metodológica da distinção para a análise linguística, e o segundo o caráter epistemológico. Carvalho lida com a apresentação de dois métodos diferentes de abordagem da língua. Arrivé vê duas perspectivas diferentes sobre o objeto.

Essa diferença dá o tom do gesto de cada leitor. Carvalho se dedica à explanação detalhada de um método sincrônico e um método diacrônico em análises linguísticas. Ele considera, nesse sentido, essencial ressaltar a primazia dada por Saussure ao estudo sincrônico da língua e justificar tal preferência com base nas noções de valor linguístico e da arbitrariedade do signo. No entanto, Carvalho não deixa de fazer uma concessão à diacronia: "[...] Saussure postula a prioridade da sincronia e, convém lembrar, prioridade não significa exclusividade" (CARVALHO, 1997, p. 93). Ele chega, inclusive, a criticar uma análise puramente sincrônica: "[...] pensamos que o conferir uma prioridade absoluta ao ponto de vista estritamente 
sincrônico resulta em um lamentável equívoco de certas correntes estruturalistas mais extremadas [...]" (CARVALHO, 1997, p. 95).

Como já dissemos, o foco de Arrivé é a discussão epistemológica. Por esse motivo, a noção de sincronia não é o foco, nesse ponto do seu texto. O tema é discutido em relação à noção de língua. A atenção, aqui, é dada à noção de diacronia, quando é levantada uma discussão sobre o problema da concepção de tempo no CLG.

A problematização se constrói em torno da pergunta sobre a existência de duas concepções de tempo no CLG. O linguista francês pergunta se existem dois modos de ação do tempo sobre a língua, um que incidiria sobre a língua como sistema (e daí a diacronia) e um outro, que teria como resultado o caráter linear do significante. Arrivé postula que há uma única concepção de tempo, a qual afeta a fala e, por consequência, a língua. Assim, na leitura de Arrivé, a linearidade do significante é uma consequência da incidência do tempo na fala, e a diacronia é "[...] a forma assumida no nível da língua por aquilo que é a linearidade no nível da fala" (ARRIVÉ, 2010, p. 92). A questão ainda se desdobra em um debate paralelo sobre a identidade do signo linguístico em suas múltiplas realizações, que é, às vezes defendida por Saussure, mas, outras vezes, negada. Arrivé vê aí uma contradição no pensamento saussuriano.

Essa problematização da concepção do tempo no CLG não é objeto da leitura de Carvalho, mesmo que ele se preocupe em tentar equilibrar as considerações sobre a sincronia e a diacronia, revelando que a ação do tempo sobre a língua não pode ser ignorada.

\section{Graus de síntese e problematização}

Como vimos no item 1 (Contextualização), há uma grande distância histórica e de condições de produção entre o PCS de Carvalho e o MER de Arrivé. Decorrente ou não dessa distância, há outra que diz respeito à visada, como mostramos no item 2 (o conteúdo do $C L G$ ). O texto de Arrivé é tomado por uma verticalidade que o de Carvalho, em função das contingências de produção, conscientemente, não almeja, e, a partir daí, como é de se esperar, ambos revelam um gesto de leitura diferente do CLG. O PCS se caracteriza pelo didatismo e pela simplicidade de exposição, o que deixa a leitura do CLG no nível do essencial, priorizando a síntese. O MER se 
caracteriza, sem deixar de ser didático, pelo tom ensaístico, o que eleva a leitura para um nível mais complexo.

$\mathrm{Na}$ exposição de Carvalho, por mais que a maioria das seções apresente uma "crítica" ao pensamento de Saussure, essa crítica é, na maioria das vezes, proveniente de um gesto de suprimento de uma falta ou de uma complementação de alguns dos postulados (ver a questão da proposta triádica do signo, da norma coseriana) do que de uma confrontação (ver a questão da arbitrariedade). $\mathrm{Na}$ exposição de Arrivé, a condução da discussão preza pela problematização e expõe as vicissitudes do que é dito no CLG, o que dá ao texto o tom de ensaio.

A postura de Carvalho é consequência de um entendimento de que o CLG é considerado uma obra "inacabada": "Trata-se, portanto, de obra póstuma e inacabada, calcada em anotações colhidas em aula por seus alunos e, como tal, explicam-se as possíveis obscuridades e contradições das ideias de Saussure" (CARVALHO, 1997, p. 26). Arrivé, por outro lado, não demonstra interesse na natureza apócrifa do CLG: "diferentemente de alguns outros leitores de Saussure, não investirei em invectivas contra os editores de 1916, nem em lamentações a respeito de outros projetos de edição" (ARRIVÉ, 2010, p, 23). Nesse sentido, ele desvaloriza o discurso sobre a natureza apócrifa do CLG e defende tanto a grandeza como a difícil execução do projeto de edição.

Como vimos na contextualização (item 1), o PCS teve sua primeira edição na segunda metade da década de 1970, poucos anos depois da tradução brasileira do CLG. Logo, não é de se esperar qualquer tipo de cotejo com os manuscritos inéditos de Saussure, acessíveis e divulgados a partir de 1996. O próprio Carvalho (1997, p. 25) afirma que "além de artigos de gramática comparada infelizmente nada mais nos legou em vida o genial mestre genebrino". Assim, o único tipo de cotejamento é feito em relação a outros poucos linguistas da época com o propósito de contrastar ou evidenciar o que é dito no CLG. No texto de Arrivé, por sua vez, os manuscritos de Saussure, que revelam suas pretensões editoriais e suas concepções sobre a natureza da linguagem, são suscitadores de discussões, sempre relacionadas à espinha do objetivo do autor na releitura do CLG.

Carvalho sintetiza e apresenta um conteúdo pronto, um obelisco, e, se há alguma reflexão, ela recai sobre esse pensamento, como produto. Arrivé explora o percurso de construção desse pensamento, as flutuações terminológicas decorrentes da dificuldade de estabelecer conceitos e as consequentes contradições inerentes a todo 
esse processo. Nesse sentido, vimos um gesto de leitura que chamamos de síntese (o de Carvalho), com intuído fundamentalmente didático de iniciação de um leitor, e outro que chamamos de problematização (o de Arrivé), cuja finalidade é também iniciar um leitor, mas se trata de "[...] uma iniciação, progressiva e propedêutica, aos arcanos das cavernas saussurianas" (ARRIVÉ, 2010, p. 94). Estamos, portanto, diante de dois gestos de leitura que se diferenciam pelo grau de síntese e problematização do conteúdo.

\section{Considerações finais}

Neste trabalho, refletimos sobre a maneira como dois autores realizam a finalidade de introduzir o CLG a leitores não iniciados em Linguística: Castelar de Carvalho, no livro Para compreender Saussure, e Michel Arrivé, no capítulo "O Curso de Linguística Geral: modesto ensaio de releitura”. De modo geral, vimos que os temas básicos do CLG (as dicotomias, a concepção de signo e suas características: arbitrariedade e linearidade) são a tônica dos dois trabalhos. Daí, realizamos uma comparação da maneira como cada um retoma e apresenta esses temas, considerando a finalidade de apresentá-los para um leitor iniciante. Essa finalidade aproxima os dois trabalhos, mas o modo de cumpri-la os distancia. O primeiro opta pela síntese, com intuído fundamentalmente didático; o outro, sem deixar de ser didático, opta pela problematização, em um percurso progressivo e propedêutico.

Esses dois gestos nos conduzem a jogar mais uma luz para o impasse que precisa ser conduzido na formação de professores e pesquisadores, sobretudo nos cursos de Letras e nos Programas de Pós-Graduação em Linguística e/ou Estudos da Linguagem, conforme destacam Azevedo, Barbosa e Moraes (2017). Segundo as autoras e o autor, há, nos desdobramentos da Linguística brasileira, a cristalização de alguns equívocos produzidos por diferentes leituras do CLG. Elas e ele assinalam, então, que "em contrapartida, cabe aos linguistas, herdeiros e professores de disciplinas dissipá-los [os equívocos], voltando-se às constantes atualizações e (re)leituras, e compreendendo que o CLG é um clássico" (AZEVEDO, BARBOSA; MORAES, 2017, p. 37).

$\mathrm{Na}$ esteira desse raciocínio, defendemos que o trabalho de identificação de gestos diferentes de leitura do CLG constitui um caminho na tarefa de dissipar os equívocos dessas leituras. 


\section{REFERÊNCIAS}

ARRIVÉ, Michel. À la recherche de Ferdinand de Saussure. Paris: PUF, 2007.

ARRIVÉ, Michel (éd). Du côté de chez Saussure. Limoges, 2008.

ARRIVÉ, Michel. Em busca de Ferdinand de Saussure. São Paulo: Parábola Editorial, 2010.

ARRIVÉ, Michel. Saussure retrouvé. Paris: Garnier, 2016.

AZEVEDO, Adélia Maria E.; BARBOSA, Jefferson Machado; MORAES, Marcilene Romeiro de. Uma (re)leitura da obra "Para compreender Saussure": fundamentos e visão crítica a partir da leitura dos prefácios do CLG e de herdeiros. In: PINHEIRO, Clemilton L.; LIMA, Maria Hozanete A. (Org.). Diálogos: Saussure e os estudos linguísticos contemporâneos, v. 3. Natal: EDUFRN, 2017, p. 21-39.

BARBOSA, Flávio de Aguiar. Uma introdução indispensável ao pensamento de Saussure. Matraga, v. 21, n. 34, 2014, p. 280-283.

CARVALHO, Castelar de. Para compreender Saussure. 7. ed. Rio de Janeiro: Vozes, 1997.

COLOMBAT, Bernard; FOURNIER, Jean-Marie, PUECH, Christian C. Histoire des idées sur le langage et les langues. Paris: Klincksieck, 2010.

CONFLUÊNCIA, números 27/28, 2004.

ELIA, Silvio. Apresentação. In: CARVALHO, Castelar. Para compreender Saussure. 7. ed. Rio de Janeiro: Vozes, 1997, p. 7-9.

MARCIONILO, Marcos. Nota do editor. In: ARRIVÉ, Michel. Em busca de Ferdinand de Saussure. São Paulo: Parábola Editorial, 2010, p. 7-8.

PUECH, Christian. Hommage - Michel Arrivé (1936-2017). Histoire Epitémologie Langage, v. 39, n. 2, 2017, p. 3-6.

SAINT-GÉRARD, Jacques-Philippe. Michel Arrivé, À la recherche de Ferdinand de Saussure. L'Information Grammaticale, n. 123, 2009. p. 58.

SAUSSURE, Ferdinand. Curso de Linguística Geral. Cultrix: São Paulo, 1995.

SOFIA. Estanislao. Ferdinand de Saussure no século XX. In: PINHEIRO, Clemilton Lopes; LIMA, Maria Hozanete A.; CALIL, Eduardo. Diálogos: Saussure e os estudos linguísticos contemporâneos, v. 1. Natal: EDUFRN, 2015, p. 19-54. 